\title{
Evaluation of College Students' Emergency Response Capability Based on Questionnaire-TOPSIS Innovative Algorithm
}

\author{
Yanyan Liu $\mathbb{D},{ }^{1}$ Wei Zhou $\mathbb{D},{ }^{2}$ and Yang Song $\mathbb{D}^{2}$ \\ ${ }^{1}$ College of Environmental Science \& Engineering, Qingdao University, Qingdao 266071, China \\ ${ }^{2}$ Department of Student Affairs, Qingdao University, Qingdao 266071, China \\ Correspondence should be addressed to Yanyan Liu; lyyfighting@126.com and Wei Zhou; jeoway@163.com
}

Received 11 May 2021; Accepted 24 June 2021; Published 6 July 2021

Academic Editor: Xiaodi Li

Copyright (c) 2021 Yanyan Liu et al. This is an open access article distributed under the Creative Commons Attribution License, which permits unrestricted use, distribution, and reproduction in any medium, provided the original work is properly cited.

With the development of our society, the diversity of the university environment has been increased. The complexity of the diversified university environment also greatly increases the frequency of campus crisis incidents. Therefore, how to evaluate the emergency response ability of college students and how to take effective response measures have become problems that need urgent attentions. In this study, the evaluation of college students' emergency response capability based on the questionnaireTOPSIS innovative algorithm is conducted. Firstly, the questionnaire method is used to analyze the current situation of college students' ability of emergency response, and then a comprehensive evaluation is made using the TOPSIS innovative algorithm. The results of the ranking of emergency response ability are as follows: excellent $>$ good $>$ undergraduate $>$ graduate $>$ inferior. Secondly, the reasons for the lack of ability of emergency response to students based on the evaluation results are studied intensively. Finally, the development countermeasures for college students' emergency response ability training are put forward.

\section{Introduction}

What is the campus crisis? The general understanding of the term "crisis" is danger, which makes our physical and psychological health or surrounding environment suffer devastating damage. However, we often ignore its deep meaning, where danger and opportunity coexist. In this way, the understanding of "crisis" is as follows: the combination of factors leads to the occurrence of certain events and situations, these events are harmful to the existence of individuals or groups, and people cannot use conventional methods and ways to solve them in a short period of time. To a certain extent, crisis puts people in a state of high pressure disintegration, and it drives people to make choices and take action to solve crisis in a state of near-collapse. It is the test of comprehensive ability and comprehensive quality of decision-maker, manager, and the parties [1]. As a kind of crisis, campus crisis has the universal definition of crisis, but it also has its special connotation. It is defined as some events that happen suddenly, which will seriously damage the personal and property safety of students and teachers, and these events occur during normal teaching time, teaching order, and the condition of the school managers, teachers, and students without any precautions $[2,3]$.

It has the characteristics of the special regional property, the directivity of the subject, and social concern. At the same time, the university campus crisis is different from the crisis of primary and junior high school campuses. Its dissemination and diffusion are faster and stronger, and it is similar to social security incidents and rule of law incidents.

Campus crises generally include the following types: natural disasters (floods, fires, wind storms, earthquakes, and so on), public safety (accidental injuries to public facilities, collapses of buildings, accidental injuries of sports equipment and experimental items, and so on), teacherstudent conflicts (correctional conflicts, corporal punishment, and so on), campus violence (bullying, verbal abuse, and physical repression), campus crime (intimidation and extortion, fights, thefts, sexual harassment, sexual crimes, and so on), campus self-harm (self-harm and suicide), cybersocial networking crises (campus online loan, fraud of online part-time job, online appointments to fight, and so on), 
occasional accident disasters (crowded stampede and traffic accident disaster), and various crises from external interference (demonstrations and gangster loan intervention) [4-6].

The risk of these campus crises always exists, such as campus violence against freshmen by four senior members of the judo department at Tenri University in Japan in May 2013, a stabbing incident at the University of Texas, USA, in May 2017, the shocking Collin Wiant incident at Ohio University in November 2018, and a student of Jinan University committed suicide in the dormitory on March 6, 2021. These individual crisis events have a high incidence in campus crisis events. Meanwhile, group crisis events also occur from time to time, such as violent protests at the University of California, Berkeley, United States, in February 2017. Henan University of Technology had a food poisoning incident with nearly 100 students in September 2020. And these group crisis events are more reflective of the inadequacy of administrators.

Therefore, in the face of many campus crises, in addition to avoiding the occurrence of crisis events from the root causes, carrying out a scientific evaluation of the emergency response ability of contemporary college students and putting forward effective emergency response measures have become an urgent work in today's colleges and universities.

\section{Evaluation of the Emergency Response Capacity of College Students' Current Situation}

2.1. Evaluation Methodology. Questionnaire Method. First, data are collected through the questionnaire method. The questionnaire consists of 20 selection questions and 2 short descriptions, which are divided into four aspects: knowledge of handling representative emergencies, access to emergency knowledge, attention to emergency knowledge, and learning desire. The questionnaire method is a statistical-based approach to processing data and obtaining laws; however, it cannot eliminate the effects of different measures; it cannot evaluate the event as a whole and draw conclusions.

TOPSIS Method. TOPSIS method is a kind of close-up ideal solution of the multiobjective decision analysis of limited scheme, also known as the distance method of good and bad solution. It is a comprehensive method of evaluating distance and does not require or limit the sample size of the evaluation object, the number of indicators, and the distribution of data. It can eliminate the impact of different evaluation indicators through the same trend and normalization treatment [7-10]. The TOPSIS method determines the optimal scheme and the worst scheme in the evaluation object by standardizing the raw data matrix. Based on the determined optimal scheme and the worst scheme, the distances between the evaluation object and the optimal scheme as well as the object and the worst scheme are calculated, respectively. These distances are used to determine how close different evaluation objects are to the optimal solution [11-15]. At the same time, all evaluation objects can be sorted according to the size of the proximity between each evaluation object and the optimal scheme, so that the evaluation object can be evaluated comprehensively $[16,17]$.

This study combines the two methods effectively. The questionnaire method is used to analyze the current situation of college students' ability of emergency response, which objectively reflects the value of various indicators in this research and makes an evaluation of the results. On this basis, we make a comprehensive evaluation of the current situation of emergency response ability of graduate and undergraduate students based on the TOPSIS method. The effective combination of questionnaire and the innovative algorithm of TOPSIS can make the evaluation method more scientific and the evaluation results closer to reality. This combination can provide a more valuable reference for taking targeted measures.

\subsection{Analysis of the Individual Index of Emergency Response} Ability of College Students Based on Questionnaire Method. In order to understand the current situation of the emergency response ability of college students, we randomly select undergraduates and graduate students for all grades in different majors to investigate, respectively. The number of graduate students is 1000 , and the number of undergraduates is 3000. The survey is conducted in the form of a questionnaire. The questionnaire consists of 20 selection questions and 2 short descriptions, which are divided into four aspects: knowledge of handling representative emergencies, access to emergency knowledge, attention to emergency knowledge, and learning desire. The results of the survey are shown in Figure 1.

As shown in Figure 1, for the overall student group's understanding of the identification of basic risk factors, accident emergency management, disaster escape techniques, and the other related knowledge, the pass rate is only $47 \%$. Most of the students for emergency knowledge are in a state of half-understanding. This fully reflects the current situation that most of the students in contemporary colleges and universities are short of the emergency knowledge. Some college students lack initiative and enthusiasm for the emergency drills organized by the school and various emergencies of the popular knowledge lecture. The emergency knowledge education work of most colleges and universities stays on the surface. The various reasons lead to the low pass rate. Graduate students have a lower pass rate than undergraduates, which may be due to the high pressure of postgraduate studies. They do not have enough time for emergency knowledge intake. This also reflects that highly educated personnel emergency knowledge is seriously inadequate, and this is a group that is easily ignored and risky.

According to Figure 2, 57\% of students do not go through the professional study of emergency knowledge, which is closely related to the lack of attention given to emergency education by schools and families. Only 5\% of students can be carried out in practice, which reflects the problem that even if we have mastered some theoretical knowledge, it has not been put into practice. At present, the 


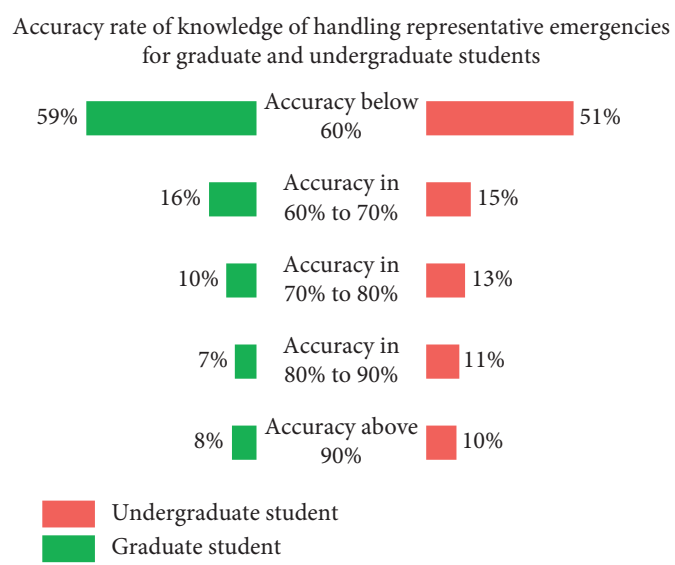

(a)

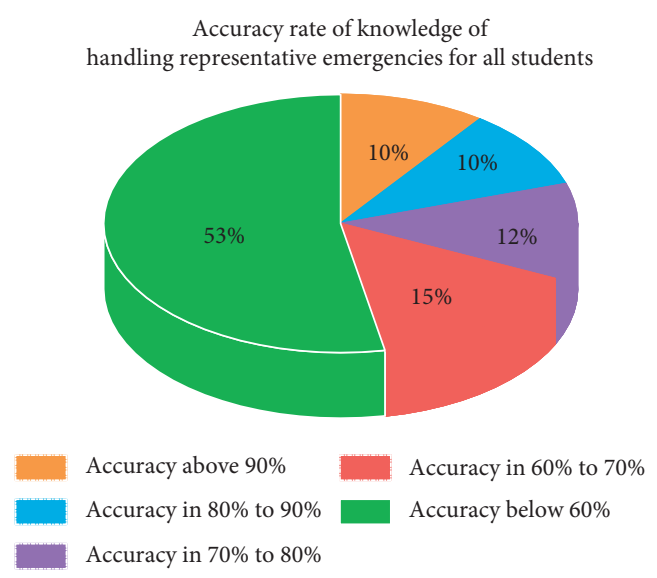

(b)

FIGURE 1: Accuracy rate of knowledge of handling representative emergencies.

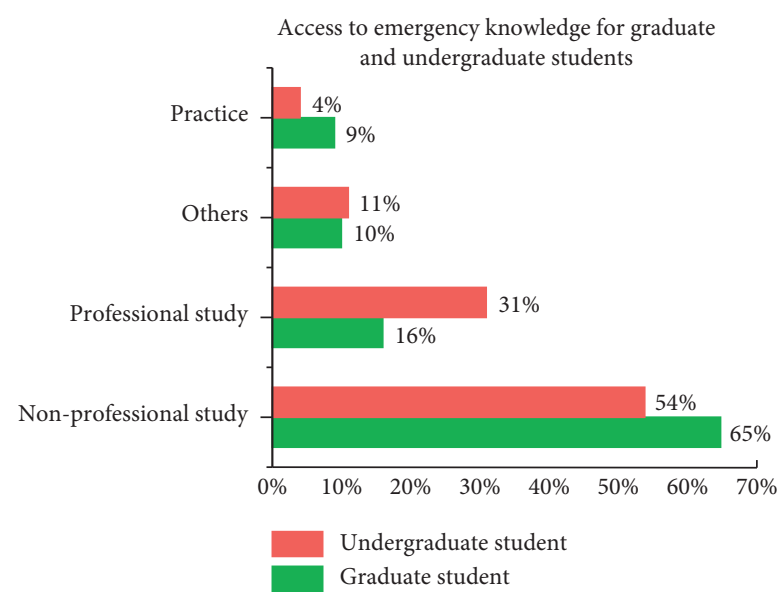

(a)

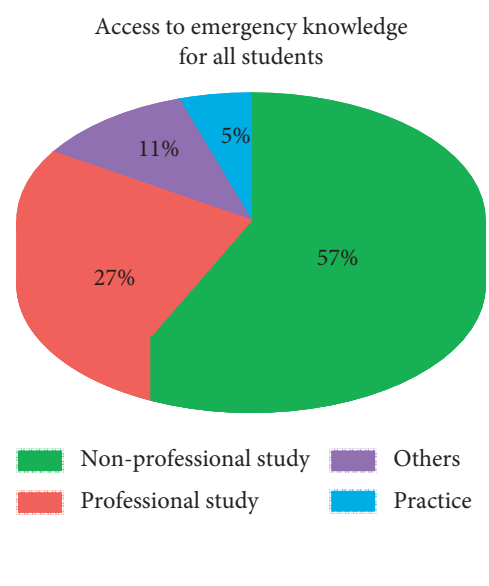

(b)

Figure 2: Access to emergency knowledge.

formalization of the emergency drill in schools and the low subjective willingness of students to participate in the emergency drill will lead to the phenomenon of "armchair strategy."

According to Figures 3 and 4, the survey found that 91\% of people showed concern about handling methods of the basic response to emergency situations and $66 \%$ of students are willing to consciously receive emergency education. This shows that college students are easy to accept and spread new things. It means that improving the knowledge of a college student's campus crisis with emergency education is effective. By comparing the attention of the graduate student group's concern with the undergraduate group's concern for emergency knowledge and the data of whether the graduate student group is willing to receive emergency education, it can be seen that the graduate student group is more concerned about the emergency knowledge and the willingness to accept emergency education is better. This indicates that the graduate group has a strong sense of concern and acceptance desire for emergency education.
In general, the analysis of the individual index of college students' emergency ability based on questionnaire method shows the following. (1) Students' storage of emergency theoretical knowledge is insufficient, and the level of emergency ability is low. (2) Students are unable to combine the small amount of theoretical knowledge they have with actual operation to reach the level of proficient application. The above problems can lead to the occurrence of a crisis. Even if students have certain emergency capacity, the impact of the burning mentality will lead to the loss of reason. This makes it difficult for students to calm response and correct solution to the crisis. In general, the overall emergency response capacity is seriously lacking, which is similar to previous studies. At the same time, we can see that the performance levels of the graduate student group and undergraduate group are different in the four aspects of the questionnaire. Its awareness and ability to deal with crisis events are uneven. A single index analysis can reflect the relative high and low value of the indicators in this study but cannot comprehensively evaluate the emergency ability of 


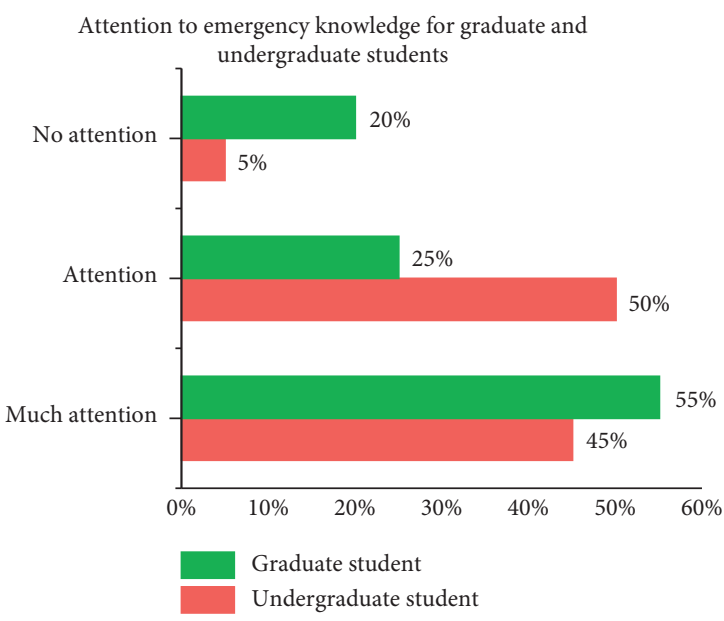

(a)

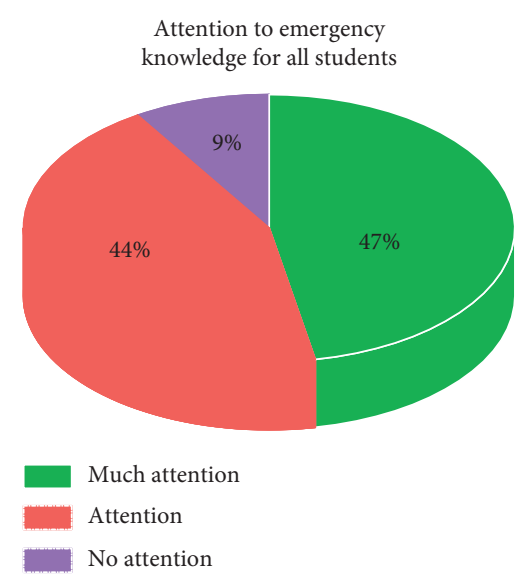

(b)

Figure 3: Attention to emergency knowledge.

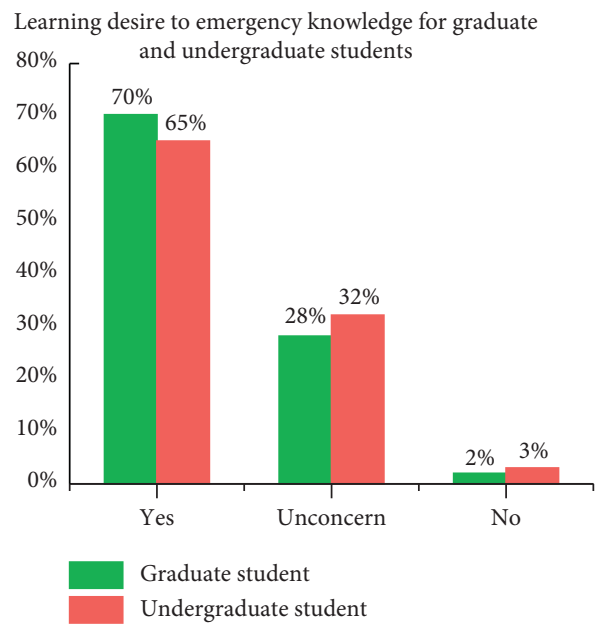

(a)

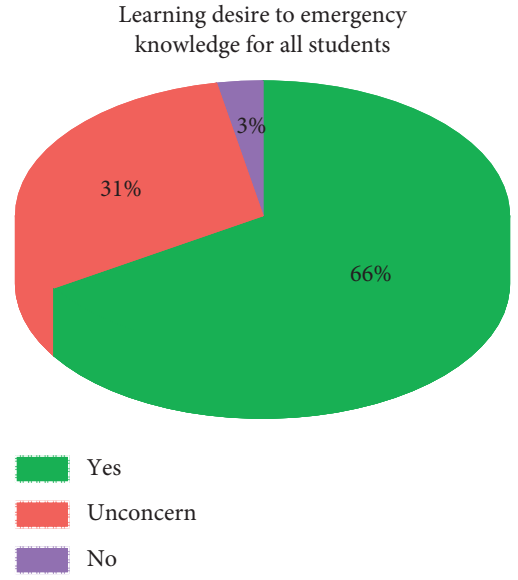

(b)

Figure 4: Learning desire to emergency knowledge.

college students and scientific judgment of the different levels of college students' emergency ability.

\subsection{Comprehensive Evaluation of the Emergency Ability of} College Students Based on TOPSIS. Based on the results of the single index analysis of the abovementioned survey statistical methods, this study uses the TOPSIS method to carry out the comprehensive evaluation of the emergency response capacity of college students.

2.3.1. TOPSIS Method Principle. The development of evaluation models offers the possibility to solve a number of scientific problems [18-26]. Chen et al. [27] first proposed the TOPSIS model, and they evaluated the advantages and disadvantages of the decision-making unit by establishing positive and negative ideal solutions and using the parameters of each decision unit in the actual problem and the relative distance of the two solutions. The best solution was to minimize the distance between positive and ideal solution and to maximize the distance between the maximization and negative ideal solution. Kacprzak [28] used sequential preference techniques to sort the ideal solution based on ordered fuzzy numbers and sort and evaluate the alternatives for group decisions. Zhang et al. [29] solved the multicriterion decision-making problem in fuzzy-covering approximate space by the TOPSIS method, i.e., selecting the most suitable material in a variety of bionanomaterials with similar properties. Wu et al. [30] proposed a new method of rock mass classification based on MCS and TOPSIS. Oenuet Soner [31] proposed waste management sites using fuzzy TOPSIS (by combining sequential preference techniques with the desired solution) and AHP (hierarchical analysis) techniques. A new group multicriteria language decision for group multicriteria language decision-making was proposed by Ou et al. [32], which was inspired by the preference level between the TOPSIS method and the two hesitant fuzzy language term sets (HFLTSs). Shi [33] and others used the 
TOPSIS method to evaluate the quality of care in the operating room. $\mathrm{Li}$ and Lei [34] made a comprehensive evaluation of the low-carbon economic development of China's subprovinces based on the TOPSIS model combined with the entropy method. In this study, the TOPSIS method is used to evaluate the emergency response capacity of college students, and the specific calculation method is as follows $[34,35]$ :

(1) Assimilation for indicator value is as follows:

$$
x_{i j}^{\prime}=\left\{\begin{array}{ll}
x_{i j}, & \text { high }- \text { class excellent indicator, } \\
\frac{1}{x_{i j}}, & \text { low - class excellent indicator, } \\
\frac{M}{\left[M+\left|x_{i j}-M\right|\right]}, & \text { medium - class excellent indicator, }
\end{array} \quad i=1,2, \ldots, n ; j=1,2,3, \ldots, m,\right.
$$

where $x_{i j}$ denotes indicator value of $j$ indicator for $i$ type student. $M$ is the ideal value of indicator.
(2) Data normalization is as follows:

$$
Z_{i j}= \begin{cases}\frac{x_{i j}}{\sqrt{\sum_{i=1}^{n}\left(x_{i j}\right)^{2}}}, & \text { (original high - class excellent indicator), } \\ \frac{x_{i j}^{\prime}}{\sqrt{\sum_{i=1}^{n}\left(x_{i j}^{\prime}\right)^{2}}}, & \text { (original low or medium - class excellent indicator). }\end{cases}
$$

(3) Determination for the best and the worst scheme is as follows:

$$
\begin{aligned}
& Z^{+}=\left(X_{1}, X_{2}, X_{3}, \ldots\right), \\
& Z^{-}=\left(Y_{1}, Y_{2}, Y_{3}, \ldots\right) .
\end{aligned}
$$

(4) Euclidean distance between indicator and best/worst scheme is as follows:

$$
\begin{aligned}
& D_{i}^{+}=\sqrt{\left(Z_{i j}-Z_{j}^{+}\right)^{2}}, \\
& D_{i}^{-}=\sqrt{\left(Z_{i j}-{ }_{Z}^{j}\right)^{2}} .
\end{aligned}
$$

(5) Approaching degree of evaluation object to the best scheme is as follows:

$$
C_{i}=\frac{D_{i}^{-}}{D_{i}^{+}+D_{i}^{-}}, \quad 0 \leq C_{i} \leq 1 .
$$

(6) The closer that $C_{i}$ is to 1 , the better the object is.

2.3.2. TOPSIS Method Evaluation Results. Based on the emergency situation and TOPSIS model method, the emergency response capacity of graduate students and undergraduates is evaluated. Four indexes such as the correct rate of emergency response, the way to obtain emergency knowledge, the attention to emergency knowledge, and the desire to learn were investigated. High-quality detailed indicators include the correct rate is more than $90 \%$, teaching in classroom, practical operation, very concerned, and willing percent in graduate and undergraduate students, respectively. Neutral detailed indicators include the percentage of graduate and undergraduate students which is $90 \%$ to $60 \%$ of the correct rate, and the other way and general attention are in the proportion of graduate and undergraduate students, respectively. Low-quality detailed indicators include the percentage of graduate and undergraduate students below $60 \%$ of the correct rate, no professional study, no concern, no want, and no willing, respectively. The original indicator value matrix is shown in Table 1 . The homogenized naturalized matrix is treated as shown in Table 2 . The best and worst vectors calculated are shown in Table 3.

According to the formula, the Euclidean distance and C value of each evaluation index and the optimal and inferior vector are calculated and sorted, as shown in Table 4.

As shown in Table 4, the results for the ranking of emergency response capacity comprehensive evaluation are as follows: excellent $>$ good $>$ undergraduates $>$ graduate students > inferior. Undergraduates have better emergency response capacity than graduate students. On the whole, 


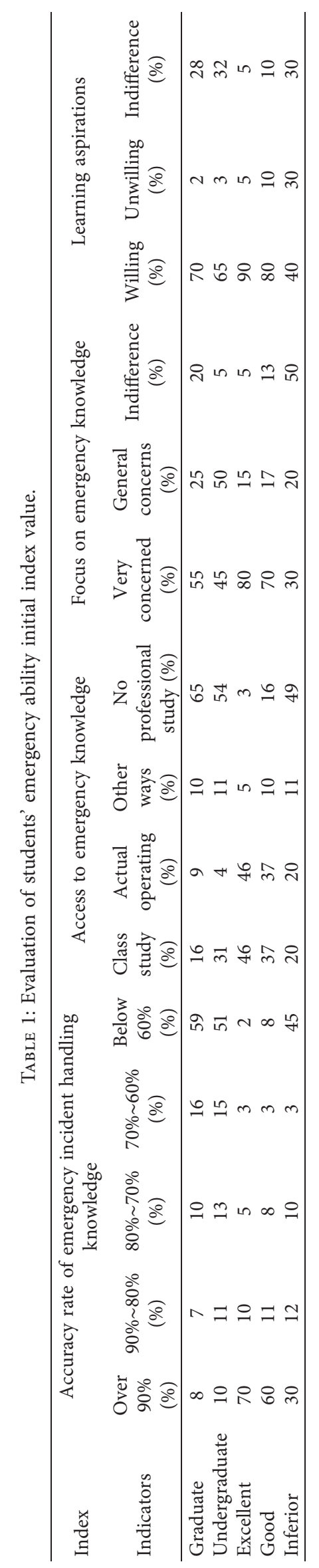




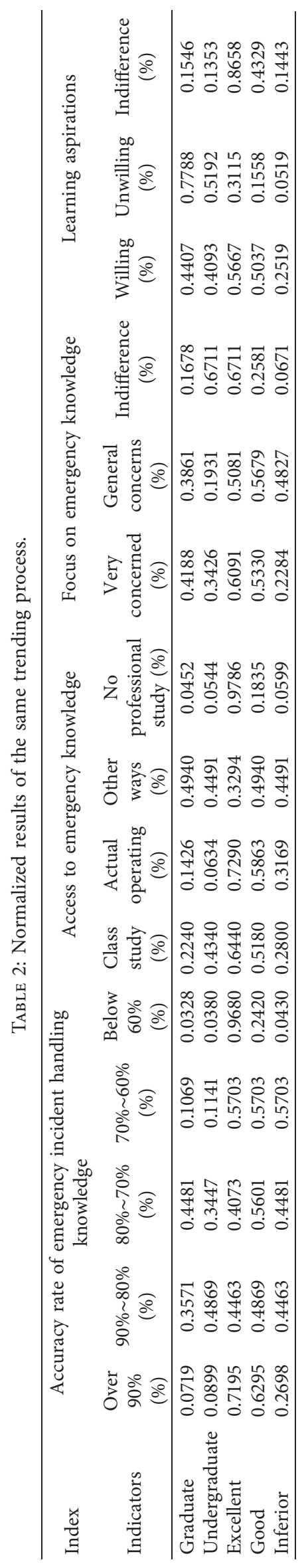


TABLE 3: The best and worst vectors calculated based on the emergency situation and the TOPSIS model method.

\begin{tabular}{lc}
\hline Name of vectors & Concrete vector \\
\hline $\begin{array}{l}\text { The best vectors calculated } \\
\text { The worst vectors }\end{array}$ & $Z_{j}^{+}=(0.7195,0.4869,0.5601,0.5703,0.9680,0.6440,0.7290,0.4940,0.9786,0.6091,0.5679,0.6711,0.5667$, \\
$\begin{array}{l}0.7788,0.8658) \\
\text { calculated }\end{array}$ & $Z_{j}^{-}=(0.0719,0.3571,0.3447,0.1069,00328,0.2240,0.0634,0.3294,0.0452,0.2284,0.3861,0.0671,0.2519$, \\
$0.0519,0.1353)$
\end{tabular}

TABLE 4: $C$ value of students' emergency ability and the result of ranking emergency ability.

\begin{tabular}{lcccc}
\hline Type of student & $D^{+}$ & $D^{-}$ & $C$ & Sort results \\
\hline Graduate & 1.9426 & 0.8092 & 0.2941 & 4 \\
Undergraduate & 1.9226 & 0.8566 & 0.3082 & 3 \\
Excellent & 0.5235 & 2.0290 & 0.7949 & 1 \\
Good & 1.3998 & 1.1451 & 0.4500 & 2 \\
Inferior & 1.9711 & 0.6454 & 0.2467 & 5 \\
\hline
\end{tabular}

graduate students and undergraduates have inferior emergency response capacity, both between good and inferior. Therefore, an in-depth analysis of the reasons for the lack of emergency response capacity and putting forward reasonable countermeasures become an urgent problem to be solved.

\section{Reason Analysis of Lack of Students' Emergency Response Ability}

Combining the realistic performance of college students in the campus crisis and evaluation results above, all the results reflect the serious lack of emergency ability of college students. There are three main reasons for this phenomenon.

3.1. Impact of Social Environment and Thought. The advent of information age, while promoting social progress, has brought advanced Internet information technology, so that contemporary students have more access to the dissemination of information. This makes the students' leisure life more colorful, broadens the knowledge level and the circle of friends, increases the insight, and broadens the horizon. However, everything has two sides; with the rapid iterative update of information, a large number of redundant information impact on the students' thinking so that their ability to identify has been reduced. At this time, some bad ideas take the opportunity to confuse their cognition, subtly change their thoughts and ideas, and thus lose themselves. Especially for junior undergraduates, because of their strong curiosity and no complicated academic burden, they are vulnerable to the influence of bad ideas and easy to set up the wrong moral values and ideas.

\subsection{Backwardness of the Management Concept and System of} Colleges and Universities. For students, the environment is wrapped in layers. Its level from outside is social-campusfamily-self. And this environment leads to the lack of emergency capacity of students. In addition to social impact, the second reason should be attributed to the school. It is understood that as of August 2017, only 150 of China's 2,879 colleges and universities have opened safety engineering programs. And there are only a few colleges and universities that offer public safety emergency courses such as escape and self-rescue and emergency rescue overview [36]. The lack of safety education in colleges and universities is a major reason for the lack of students' emergency knowledge. Most of the ways for students to obtain emergency knowledge come from teaching in classroom and family education. However, there are few systematic education systems and prevention systems for campus crisis in colleges and universities. Failure to take effective measures to prevent and block the occurrence of crises from the root causes has led to frequent campus crises events. In addition, colleges and universities have not perfected the corresponding emergency response system so that the crisis cannot be quickly contained. And it is difficult to obtain timely redress in the aftermath of a crisis. It cannot be stopped in time, resulting in the crisis causing adverse effects and sequelae. The occurrence of a campus crisis has caused some impact and change on the concept and thought of college teachers and students, and to a certain extent, it affects the stability and atmosphere of the campus environment.

3.3. Lack of Awareness among College Students. For both undergraduate and graduate students, they have been educated for more than a decade before entering the university campus. The educational experience has made them form an independent thought, ideas, and unique character. However, these thought and ideas have the nature of "ivory tower," which has a certain degree of immaturity and simplicity relative to the complex social environment. Like the "barrel principle," this immaturity would immediately playout when an emergency is encountered as a shortboard effect. This can lead to a situation where the student's mentality and reason suffered shock, collapse, and a tragic event caused by confused thinking or impulsivity. In addition, even if the students still have rational existence, they are mostly teenagers who grow up in care, lack of experience, and ability to be independent. Moreover, students lack practical operation in ordinary times, so they can only passively accept the damage caused by the crisis.

\section{College Students' Emergency Capacity Training Countermeasures}

4.1. Improve Corresponding Rules and Regulations and Promote the Construction of a Safety Education System. First of all, if the corresponding rules and regulations are not formulated, there will be no rules to follow. The rules and regulations protect teachers and students before a crisis 
occurs. It regulates the behavior of teachers and students on campus to prevent the occurrence of crises and isolate the incentives that cause them. The rules and regulations are "guide signs" to guide the right direction in the chaos when a crisis occurs. It ensures that the most basic remedial measures are carried out in an orderly manner and to avoid greater harm caused by the chaos and disorder of the scene. Schools should formulate corresponding campus regulations and emergency plans to provide scientific, correct, and powerful theoretical basis and methods for responding to campus crisis events [37]. Through daily compliance and learning, students form daily habits and clear cognition so as to reduce the occurrence of crisis events and improve students' ability to respond to crisis events.

Universities should establish a systematic and safe campus education system. Teachers infiltrate crisis education in daily classroom teaching and convey concepts such as personal safety, traffic safety, and social safety to students. In this way, students are guided to gradually form their own unique sense of sensitivity, perceive from different angles and details, and discover potential crisis information in the campus environment. It is necessary to learn to further identify the importance and credibility of information and master the focus of information. The student's crisis early warning ability should be cultivated. For example, the campus loan incidents have a serious impact. For students who intend to participate in campus loans, most of them participate because of unexpected events in their lives and urgent need for money. They often have many abnormal behaviors in their daily lives. If the students around them can find these details and signals in time, understand their psychological thoughts, convey the harm of the relevant events, and temporarily stabilize their emotions through communication, more time to report to the counselor would be gained and problem can be solved. If students have certain early warning capabilities, they can perceive the advent of a crisis and respond in a timely manner based on the signs that appear. Schools can prepare corresponding campus safety manuals based on school conditions, which can be used as written textbooks for safety education and used in safety education classroom teaching $[38,39]$. The manual should guide students to identify the content and nature of crises, familiarize themselves with the basic measures and methods of crisis handling, strengthen students' ability to develop basic rapid response, prevention, and early warning capabilities, and master certain risk control skills to achieve the basis of grasping crisis-related theoretical knowledge. It allows students to make scientific and decisive decisions based on crisis information and play an effective role in intervention. Of course, it is still difficult to solve the crisis by relying on the ability of the student group alone. Through daily safety education, the connection between the school and the students can be established so as to achieve the goal of communication and order and establish a complete campus crisis management system. After a campus emergency, under the complete information management system, students can obey the school's unified deployment and the school's official information release. And students can achieve correct information, abandon false information, cooperate with the school to control the development of the situation, and do their best to cooperate with the school to deal with campus safety incidents.

\subsection{Implement Simulations to Examine Students' Emergency} Response Capabilities. The previous survey results also reflect a phenomenon as follows: even if students have a certain theoretical foundation, they cannot apply this knowledge to practice, which is basically a matter of fact. Therefore, while the school promotes safety education into the classroom, it should also conduct regular practical exercises for students to achieve the dual purpose of reviewing theoretical knowledge and testing emergency response capabilities.

The school can formulate corresponding simulation training in combination with the safety manual prepared. It can also formulate various campus emergencies that may occur in combination with the actual school situation and regularly lead students to train in different real scenarios in groups, as a form of reviewing safety education. After the drill, a group summary will be conducted, and the teachers and students will understand the specific situation and the safety education required at each stage through the summary. Through simulation training, students who combine theory with practice can skillfully use various processing methods, and their psychological endurance has been improved to a certain extent. Finally, theoretical knowledge, actual combat exercises, and psychological ability are perfected.

Daily training ensures that students are proficient in the application of theoretical knowledge. However, campus safety incidents are uncertain and always dynamic. Although corresponding emergency plans have been formulated, they must be applied and changed flexibly in the actual process. This requires students to break the formulation of fixed theories on the basis of mastering the basic processing methods and completes the process of "decomposing old theories-assembling new theories" in conjunction with specific events. The handling of crisis events is targeted and planned. Students can adjust and respond calmly at any time according to the complete emergency plan established by themselves and finally reach the level of strategic planning.

4.3. Innovative Ways to Guide Psychological Counseling and Adjust Students' Recovery Ability. The entire process of "preliminary brewing-intense occurrence-calming down" of emergencies swept across the entire campus like a typhoon, causing varying degrees of a psychological and physical shock to students. Symptoms such as anxiety and panic may occur. Although daily safety education includes psychological construction, it is all preconstruction before the crisis. There are certain individual differences between different students. This difference includes both the appearance of different preconstruction effects and the postcrisis psychological changes. The daily psychological quality education of the school is designed according to the commonality of students, but the personality part of each person is not involved. And the traditional classroom education model 
cannot realize the systematic psychological guidance of each student. So, this requires the school to establish a cloud database based on the school's situation with the help of the Internet platform while carrying out the traditional classroom psychological quality education and mental health education. Under the guidance of professional psychologists, we summarize and sort out existing psychological counseling methods and establish multiple sets of psychological adjustment models. And it is updated and maintained constantly according to the occurrence of subsequent crisis events. Each student has his own independent account and conducts regular psychological questions and answers. He can open his heart to the maximum and accept the most systematic psychological guidance in a relatively hidden environment whether in daily campus life or when suffering a major psychological impact. Under the premise of ensuring the privacy of students, professional teachers analyze the background data, conduct face-to-face conversations with individual serious students, and follow up on the students' psychological conditions in time. This psychological guidance system that combines the traditional classroom model and the innovative network model can realize the school's comprehensive psychological quality education for students to the greatest extent. It can also seamlessly connect the psychological construction of students before and after the crisis, improve students' psychological endurance and self-healing ability, guide students to sum up, and increase the experience of self. To a certain extent, it can also ensure that students' psychology is always in a healthy state so as to avoid some campus safety incidents caused by individual students' psychological problems.

\subsection{Accurately Implement Policies Based on the Characteristics} of Students and Focus on Targeting. Based on the characteristics of undergraduates and graduate students, the cultivation of their emergency response capabilities should be guided by the circumstances and be implemented precisely. Graduate students have high academic qualifications, and their educational experience makes them pay more attention to emergency knowledge and they are willing to receive emergency education. However, their education stage has caused them not have enough time to learn and understand seriously and carefully the knowledge about campus crisis events. Based on the current situation of graduate students, it is necessary to explore efficient and effective ways for the graduate students to acquire knowledge and capabilities about campus crises. The role of mass media and the Internet in popularizing emergency knowledge can be utilized to enable graduate students to quickly improve themselves processing power in crisis events.

Undergraduates' attention to emergency knowledge and willingness to receive emergency education are not as high as those of graduate students, which may be related to the current emergency education mode. It is because of the lack of education on emergency disaster prevention and first aid skills in colleges and universities. In response to this, student crisis education should be included in the normal education plan of school education. Student crisis education becomes a required course for students in universities and colleges, making it linked to student credits, and passing this method forces college students to learn emergency knowledge. And, this further arouses students' disgust; this is mainly because emergency education in most colleges and universities is mostly traditional classroom theory teaching, which is less attractive to students. Firstly, in order to arouse students' interest, the mode of emergency education can be changed to a practical form so that students can personally operate emergency facilities to master their use. By enhancing students' hands-on ability and strengthening their psychological quality, they can achieve better "achievements" in the "actual combat" of the campus crisis. Schools should improve students' interest and enthusiasm by optimizing the classroom form of crisis education. Secondly, teachers should improve their personal charm. Teachers should continuously improve their knowledge while spreading knowledge to students. Through ordinary observation, we can find that teachers who are witty, humorous, and knowledgeable are more likely to be welcomed by students so as to get a better classroom experience, and students will be more serious.

\section{Conclusions}

In summary, this research gained insight into the evaluation of college students' emergency response capability based on the questionnaire-TOPSIS innovative algorithm. Firstly, the questionnaire method was used to analyze the current situation of college students' ability of emergency response, and then a comprehensive evaluation was made using the TOPSIS innovative algorithm. The results of the investigation and statistical analysis show that students have a relatively scarce store of emergency response theory knowledge and a low level of emergency response capability. Students are unable to combine the small amount of theoretical knowledge they have with actual operation to reach the level of proficient application. Even though college students have a certain emergency response ability, the impact of anxious mentality will cause a loss of calmly respond and correctly resolve the crisis. The TOPSIS comprehensive evaluation results are excellent $>$ good $>$ undergraduate $>$ graduate $>$ inferior. The emergency response ability of undergraduates is better than that of graduate students, but in general, the emergency response ability of graduates and undergraduates is inferior, and both are between good and inferior. Therefore, an indepth analysis of the reasons for the lack of emergency response capabilities and reasonable countermeasures has become problems that need to be resolved.

This study focused on the influence of educational background on students' emergency response ability. In contrast, emergency response ability is influenced by numerous factors, such as students' own gender, age, personality, physical condition, school, and social environment. Blair et al. [40] studied the safety beliefs and behaviors of Midwestern college students in the United States and found that female students had stronger safety beliefs and behaviors than male students of the same age. And, Liu et al. 
[41] studied the level of emergency knowledge of college students and found that there were significant differences in college students' emergency abilities with respect to age. In addition, family education also has an important influence on students' emergency response ability. Scientific and reasonable family education is the key of students' healthy growth and the formation of a sound personality. The influence of these influencing factors on emergency response ability is obvious but not studied in this study, and further research can be conducted on the influence of various influencing factors on students' emergency response ability.

College students' emergency response capabilities should be further improved for the campus crisis which is widespread nowadays. Under the traditional Chinese education model, students' educational experience before entering university is passive. To a certain extent, their minds are not yet matured. It is unrealistic to rely on their own strength to improve their emergency response capabilities. This requires colleges and universities to follow the halfopen mode of education and establish a "precrisis knowledge education and psychological construction-systematic guidance, stable mentality maintainability during the crisis, and postcrisis psychological counseling and summary error correction" chain-style campus security incident handling system in view of the three states of campus safety incidents (before, during, and after). Through "system construction + simulation + psychological counseling + precise policy implementation," the students' ability of comprehensive emergency response will gradually improve, the incidence of campus safety incidents will gradually decrease, and the loss of campus after the crisis will gradually reduce.

\section{Data Availability}

The data used to support this study are included within the manuscript.

\section{Conflicts of Interest}

The authors declare that they have no conflicts of interest.

\section{References}

[1] M. Jian, Innovative Strategies Crisis Management for Universities: Realistic Choice of the Stability of the Higher Institutions, China Procuratorial Press, Beijing, China, 2007.

[2] J. Mastrodicasa, "Technology use in campus crisis," New Directions for Student Services, vol. 2008, no. 124, pp. 37-53, 2010.

[3] M. Shaw, "Teaching campus crisis management through case studies: moving between theory and practice," Journal of Student Affairs Research and Practice, vol. 55, no. 1, pp. 1-14, 2018.

[4] J. L. Christina, "College of the overwhelmed: the campus mental health crisis and what to do about it," Journal of the American Academy of Child \& Adolescent Psychiatry, vol. 44, no. 12, pp. 1317-1318, 2005.

[5] M. Kennedy, Crisis on Campus, Vol. 79, MIT Press, Cambridge, MA, USA, 2007.

[6] R. Eaker and J. Viars, "Campus crisis response at Viberg college," Journal of Cases in Educational Leadership, vol. 17, no. 4, pp. 86-95, 2014.
[7] H. Deng, C.-H. Yeh, and R. J. Willis, "Inter-company comparison using modified TOPSIS with objective weights," Computers \& Operations Research, vol. 27, no. 10, pp. 963973, 2000.

[8] J. Cheng, W. Zhang, H. Yang, X. Su, T. Ma, and X. Chen, “A seed-expanding method based on TOPSIS for community detection in complex networks," Complexity, vol. 2020, Article ID 9017239, 14 pages, 2020.

[9] M. S. Yang, Z. Hussain, and M. Ali, "Belief and plausibility measures on intuitionistic fuzzy sets with construction of belief-plausibility TOPSIS," Complexity, vol. 2020, Article ID 7849686, 12 pages, 2020.

[10] W. Zhang, X. Zhang, F. Liu, Y. Huang, and Y. Xie, "Evaluation of the urban low-carbon sustainable development capability based on the TOPSIS-BP neural network and grey relational analysis," Complexity, vol. 2020, Article ID 6616988, 16 pages, 2020.

[11] Y.-J. Lai, T.-Y. Liu, and C.-L. Hwang, "TOPSIS for MODM," European Journal of Operational Research, vol. 76, no. 3, pp. 486-500, 1994.

[12] M. Behzadian, S. Khanmohammadi Otaghsara, and J. Ignatius, "A state-of the-art survey of TOPSIS applications," Expert Systems with Applications, vol. 39, no. 17, pp. 1305113069, 2012.

[13] D. L. Olson, "Comparison of weights in TOPSIS models," Mathematical \& Computer Modelling, vol. 40, no. 7-8, pp. 721-727, 2004.

[14] X. B. Liu, Y. J. Zhang, and W. K. Cui, "Development assessment of higher education system based on TOPSIS-entropy, hopfield neural network, and cobweb model," Complexity, vol. 2021, Article ID 5520030, 11 pages, 2021.

[15] M. Lin, C. Huang, and Z. Xu, "TOPSIS method based on correlation coefficient and entropy measure for linguistic pythagorean fuzzy sets and its application to multiple attribute decision making," Complexity, vol. 2019, Article ID 6967390, 16 pages, 2019.

[16] C. Mao, "Research on university campus crisis and countermeasures," Technology and Economic Guide, vol. 35, 2016.

[17] H. S. Shih, H. J. Shyur, and E. S. Lee, "An extension of TOPSIS for group decision making," Mathematical \& Computer Modelling, vol. 45, no. 7-8, pp. 801-813, 2007.

[18] X. Liu and H. Yu, "Continuous adaptive integral-type sliding mode control based on disturbance observer for PMSM drives," Nonlinear Dynamics, vol. 104, no. 2, pp. 1429-1441, 2021.

[19] J. Yu, P. Shi, J. Liu, and C. Lin, "Neuroadaptive finite-time control for nonlinear MIMO systems with input constraint," IEEE Transactions on Cybernetics, vol. 99, pp. 1-8, 2020.

[20] X. Li, X. Yang, and T. Huang, "Persistence of delayed cooperative models: impulsive control method," Applied Mathematics and Computation, vol. 342, pp. 130-146, 2019.

[21] C. Fu, Q.-G. Wang, J. Yu, and C. Lin, "Neural network-based finite-time command filtering control for switched nonlinear systems with backlash-like hysteresis," IEEE Transactions on Neural Networks and Learning Systems, vol. 99, pp. 1-6, 2020.

[22] H. Zhang, J. Yu, Y. Ma, Z. Pan, and J. Zhao, "Image restoration based on stochastic resonance in a parallel array of fitzhugh-nagumo neuron," Complexity, vol. 2020, Article ID 8843950, 9 pages, 2020.

[23] J. Hu, G. Sui, X. Lv, and X. Li, "Fixed-time control of delayed neural networks with impulsive perturbations," Nonlinear Analysis: Modelling and Control, vol. 23, no. 6, pp. 904-920, 2018. 
[24] J. Zhao, Y. Ma, and Z. Pan, "Research on image signal identification based on adaptive array stochastic resonance," Journal of Systems Science and Complexity, vol. 2021, no. 10, 2021.

[25] J. P. Yu, P. Shi, and X. K. Chen, Finite-Time Command Filtered Adaptive Control for Nonlinear Systems via Immersion and Invariance, Science China Information Sciences, Beijing, China, 2021.

[26] T. Xu, H. Yu, and J. Yu, "Finite-time control for a coupled four-tank liquid level system based on the port-controlled Hamiltonian method," Complexity, vol. 2020, Article ID 5320756, 14 pages, 2020.

[27] Y. Chen, J. Liu, and Q. An, "Analysis and research on car sales service satisfaction based on statistics and AHP," China Collective Economy, vol. 21, pp. 75-77, 2009.

[28] D. Kacprzak, "An extended TOPSIS method based on ordered fuzzy numbers for group decision making," Artificial Intelligence Review, vol. 53, no. 3, pp. 2099-2129, 2020.

[29] K. Zhang, J. Zhan, and Y. Yao, "TOPSIS method based on a fuzzy covering approximation space: an application to biological nano-materials selection," Information Sciences, vol. 502, pp. 297-329, 2019.

[30] L. Z. Wu, S. H. Li, and M. Zhang, "A new method for classifying rock mass quality based on MCS and TOPSIS," Environmental Earth Sciences, vol. 78, no. 6, 2019.

[31] S. Oenuet and S. Soner, "Transshipment site selection using the AHP and TOPSIS approaches under fuzzy environment," Waste Management, vol. 28, no. 9, pp. 1552-1559, 2008.

[32] Y. Ou, L. Yi, B. Zou, and Z. Pei, "The linguistic intuitionistic fuzzy set TOPSIS method for linguistic multi-criteria decision makings," International Journal of Computational Intelligence Systems, vol. 11, no. 1, p. 120, 2018.

[33] S. Shi, "Comprehensive evaluation of nursing quality in operating rooms of tertiary grade A hospitals based on TOPSIS method," Chinese Nursing Research, vol. 11, 2019.

[34] S. Li and M. Lei, "TOPSIS based assessment of low carbon economy development and spatial econometric analysis," Chinese Journal of Management Science, vol. S1, 2014.

[35] X. Ao, P. Fu, and Q. Liu, "Comprehensive evaluation using DTOPSiS method and grey correlation method analysis and research on alfalfa introduction test," Prataculture \& Animal Husbandry, vol. 5, pp. 7-10, 2010.

[36] P. Guo, "Research on crisis education and emergency ability training for college students in China," Research in Teaching, vol. 36, no. 3, pp. 19-21, 2013.

[37] L. Wang, L. Li, and J. Zeng, "Study and practice on the promotion of emergency prevention and protection capability for college students," Journal of Catastrophology, vol. 33, no. 2, pp. 172-176, 2018.

[38] W. W. Shelley, J. T. Pickett, and C. Mancini, "Race, bullying, and public perceptions of school and university safety," Journal of Interpersonal Violence, vol. 36, no. 1-2, pp. NP824-NP849, 2017.

[39] A. L. Etopio, P. Devereux, and M. Crowder, "Perceived campus safety as a mediator of the link between gender and mental health in a national U.S. college sample," Women \& Health, vol. 59, no. 7, pp. 703-717, 2018.

[40] E. H. Blair, D.-C. Seo, M. R. Torabi, and M. A. Kaldahl, "Safety beliefs and safe behavior among midwestern college students," Journal of Safety Research, vol. 35, no. 2, pp. 131-140, 2004.

[41] Y. Liu, Y. H. Hao, and H. Sun, "Emergency manage knowledge among college students and associated factors in Heilongjiang province," Chinese Journal of School Health, vol. 36, no. 3, pp. 330-332, 2015. 